\title{
Capsule Commentary on Sabbatini et al., Controlling Health Costs: Physician Responses to Patient Expectations for Medical Care
}

\author{
Elaine H. Morrato, DrPH MPH \\ Colorado School of Public Health, University of Colorado, Anschutz Medical Campus, Aurora, CO, USA.
}

$\mathrm{J}$ Gen Intern Med 29(9): 1272

DOI: $10.1007 / \mathrm{s} 11606-014-2929-3$

(c) Society of General Internal Medicine 2014

$\mathrm{T}$ he health care triple aim is better health, better care, and lower costs. To address costs, health systems and physicians are being challenged to make better value-based decisions and take greater societal responsibility when selecting diagnostic testing and treatment options for their patients. Partnered with more than 60 specialty societies, the Choosing Wisely campaign exemplifies this effort and aims to educate the public about the appropriate use of tests or procedures. ${ }^{1}$ Moreover, a recent review of clinical guidelines issued by the largest physician societies found that half explicitly integrate costs into their deliberations. ${ }^{2}$

Given this context, the qualitative study by Sabatini et al. $^{3}$ explored how physicians are balancing the needs and demands of their patients when trying to be good fiscal stewards of health care resources. Specifically, this set of nine focus groups involving 62 mid-west primary care and specialty physicians discussed how they manage the tension between perceived responsibility to practice cost-consciously and the desire to satisfy patient expectations. The authors learned that it is very challenging to operationalize prudent use of health care resources at the front lines of clinical practice. Physicians are using a variety of educational, trustbased, and substitution strategies to address the challenge of shared decision-making with patients.

One novel aspect of this study is how costs were framed from a broader perspective in the decision-making process.
As the authors argue, cost comparisons include not just the direct cost of a test or service but also indirect costs, such as: physician time to build trust and educate patients; patient time and convenience; and psychological costs associated with perceived "peace-of-mind" benefits vs. harms. Being cost conscious is complex and nuanced.

Policies and programs designed to promote wise use of health care services should address the effects of both direct and indirect costs on shared decisions if we are to adopt those behaviors into practice. More work is needed to understand physician and patient perceptions, as they will vary between clinical decisions and settings. Only then can appropriate cost-conscious dissemination and implementation strategies be developed and supported.

Conflict of Interest: The author has no conflicts of interest.

Corresponding Author: Elaine H. Morrato, DrPH MPH; Colorado School of Public Health, University of Colorado, Anschutz Medical Campus, Aurora, CO 80045, USA (e-mail: Elaine.morrato@ucdenver.edu).

\section{REFERENCES}

1. Cassel CK, Guest JA. Choosing wisely: helping physicians and patients make smart decisions about their care. JAMA. 2012;307(17):1801-2.

2. Schwartz JAT, Pearson SD. Cost consideration in the clinical guidance documents of physician specialty societies in the United States. JAMA Intern Med. 2013;173(12):1091-1097.

3. Sabbatini AK, Tiburt JC, Campbell EG, Sheeler RD, Egginton JS, Goold SD. J Gen Intern Med. 2014. doi:10.1007/s11606-014-2898-6.

Published online July 4, 2014 